\title{
TELE-AAC RESOLUTION
}

KATE ANDERSON, B. APP. SC. (HONS), MSPAA ${ }^{1}$,

MICHELLE K. BOISVERT, PHD, CCC-SLP²,

JANIS DONESKI-NICOL, MS, CCC-SLP, ATP3,

MiCHelle L. GUTMANN, PHD, CCC-SLP4, Nerissa C. HAll, MA, CCC-SLP5, CYNTHIA MORELOCK, MS, CCC-SLP' RICHARD STEELE, PHD ${ }^{7}$, ELLEN R. COHN, PHD, CCC-SLP8

${ }^{1}$ UNIVERSITY OF SYDNEY, AUSTRALIA

${ }^{2}$ UNIVERSITY OF MASSACHUSETTS, AMHERST, MA

${ }^{3}$ UNIVERSITY OF MASSACHUSETTS, AMHERST, MA

${ }^{4}$ Department of Hearing and SPEech SCIEnCES, VANDERbilt University, NASHVille, TN

${ }^{5}$ UNIVERSITY OF MASSACHUSETTS, AMHERST, MA

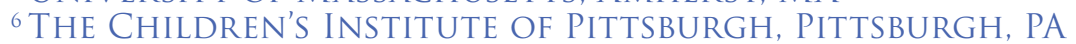

${ }^{7}$ LINGRAPHICA, PRINCETON, NJ

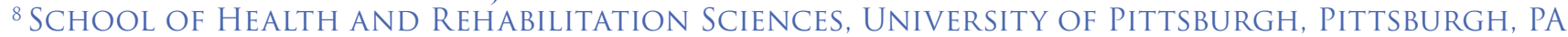

\section{ABSTRACT}

Approximately $1.3 \%$ of all people, or about 4 million Americans, cannot rely on their natural speech to meet their daily communication needs. Telepractice offers a potentially cost-effective service delivery mechanism to provide clinical AAC services at a distance to the benefit of underserved populations in the United States and worldwide. Tele-AAC is a unique cross-disciplinary clinical service delivery model that requires expertise in both telepractice and augmentative and alternative communication (AAC) systems. The Tele-AAC Working Group of the 2012 ISAAC Research Symposium therefore drafted a resolution underscoring the importance of identifying and characterizing the unique opportunities and constraints of Tele-AAC in all aspects of service delivery. These include, but are not limited to: needs assessments; implementation planning; device/system procurement, set-up and training; quality assurance, client progress monitoring, and follow-up service delivery. Tele-AAC, like other telepractice applications, requires adherence to the ASHA Code of Ethics and other policy documents, and state, federal, and international laws, as well as a competent technological infrastructure. The Working Group recommends that institutions of higher education and professional organizations provide training in TeleAAC service provision. In addition, research and development are needed to create validity measures across Tele-AAC practices (i.e., assessment, implementation, and consultation); determine the communication competence levels achieved by Tele-AAC users; discern stakeholders' perceptions of Tele-AAC services (e.g., acceptability and viability); maximize Tele-AAC's capacity to engage multiple team members in AAC assessment and ongoing service; identify the limitations and barriers of Tele-AAC provision; and develop potential solutions.

Key words: Tele-AAC, Augmentative and Alternative Communication (AAC), telepractice

\section{RESOLUTION}

\section{WHEREAS:}

\section{People with complex communication needs may benefit from the use of Augmentative and Alternative Communication (AAC). Examples of AAC include manual} signing, letter boards, communication books and hightech speech generating devices. Beukelman and Mirenda (2012) reported that approximately $1.3 \%$ of all people, or about 4 million Americans, cannot rely on their natural speech to meet their daily communication needs. For adults, the prevalence of complex communication needs
(CCN) increases with age, and is significantly higher amongst those living in residential care facilities (Hirdes, Ellis-Hale \& Pearson Hirdes, 1993). Prevalence rates of $0.6 \%$ have been reported for school-aged children (Matas, Mathy-Laikko, Beukelman \& Legresley, 1985), while Binger and Light (2006) report that for preschoolers receiving special education, the prevalence of CCN may be as high as $12 \%$. 


\section{WHEREAS:}

Research suggests that the supports available to individuals who use AAC and their families fall short of their needs. Families of children who use AAC interviewed in the US, UK, and Australia have reported a shortage of technical support, intervention, advocacy, and training around their child's AAC device, and feel that they often have to carry these responsibilities alone (Goldbart \& Marshall, 2004; Marshall \& Goldbart, 2008; McNaughton et al., 2008). Factors contributing to this shortfall are varied, and include: limitations in staffing, funding, and resources; geographical and logistical barriers to service access; and shortage of professionals trained and experienced in AAC service provision (lacono \& Cameron, 2009; McNaughton, et.al, 2008).

\section{WHEREAS:}

Telepractice offers a potentially cost-effective service delivery mechanism to provide clinical AAC services at a distance to the benefit of underserved populations in the United States and worldwide. Telepractice has been reported to improve patient access to services, increase cost-effectiveness and efficiency of service provision, and facilitate access to specialist consultation when required (Mashima \& Doarn, 2008). Telepractice has been used with success in many areas of speech-language pathology practice, including fluency and voice disorders, child speech and language delay, acquired communication disorders (Mashima \& Doarn, 2008), and the team management of developmental disabilities such as Autism Spectrum Disorder (Boisvert, Lang, Andrianopoulos \& Boscardin, 2010).

\section{WHEREAS:}

Tele-AAC is a unique cross-disciplinary clinical service delivery model that requires expertise in both telepractice and augmentative and alternative communication (AAC) systems.

\section{WHEREAS:}

Tele-AAC, like other telepractice applications, requires adherence to the ASHA Code of Ethics and other policy documents, and state, federal, and international laws.

\section{WHEREAS:}

Competent implementation of Tele-AAC is contingent upon an appropriate and adequate technological infrastructure. This includes, but is not limited to hardware/software, Internet, telecommunications, and trained personnel.

\section{WHEREAS:}

As identified by the person who uses Augmentative and Alternative Communication (PWUAAC), Tele-AAC should address the needs of the PWUAAC's circle of communication partners.

\section{WHEREAS:}

Tele-AAC offers the ability to coordinate care across multiple essential direct and indirect service providers. According to the World Health Organization's World Report on Disability (WHO, 2011), services for people with disability often require input across multiple service providers and health care sectors. In reality, services to people with a disability, including those with $\mathrm{CCN}$, are often fragmented or unnecessarily duplicated (WHO, 2011). Tele-AAC can facilitate the coordinated participation of clinical team members; service delivery recipients and their caregivers; and medical personnel. Tele-AAC team-based approaches require adequate technical infrastructure, and a range of clinical methods, strategies, and resources.

\section{WHEREAS:}

Tele-AAC is a valuable clinical service delivery model that includes assessment, therapy, and follow-up services, each of which is deserving of reimbursement. Citing a study by Kairy, Lehoux, and Vincent, (2009), the World Health Organization affirmed that "telepractice leads to similar or even better clinical outcomes when compared to conventional interventions" (WHO, 2011, p. 119), and is a reasonable accommodation to improve service access (WHO, 2011).

\section{RESOLVED:}

The Working Group recommends that Tele-AAC services promote and advance the development of the highest level of communication competence. 


\section{RESOLVED:}

The Working Group recommends that Tele-AAC practitioners demonstrate adequate technical competency, maintain appropriate licensure, and employ principles of evidence-based practice.

\section{RESOLVED:}

The Working Group recommends that it is important to identify and characterize the unique opportunities and constraints of Tele-AAC in all aspects of service delivery. These include, but are not limited to: needs assessments; implementation planning; device/system procurement, set-up and training; quality assurance, client progress monitoring, and follow-up service delivery.

\section{RESOLVED:}

The Working Group recommends that institutions of higher education and professional organizations provide training in Tele-AAC service provision. Training should convey the theoretical foundations in combination with hands-on, clinical practicum experience and cover all aspects of service delivery, collaborative teaming, and available technology and resources.

\section{RESOLVED:}

The Working Group recommends that stakeholders such as professional special interest groups and associations encourage the advancement of TeleAAC. Potential strategies include the conduct of inter-professional continuing education programming; development of Tele-AAC standards and guidelines; identification of new opportunities for the extension of Tele-AAC and infrastructure integration; stimulation of Tele-AAC research; and advocacy for reimbursement and interstate license portability.

\section{RESOLVED:}

The Working Group recommends that research and development in Tele-AAC involve and value the input of PWUAAC. Research and development are needed to create validity measures across TeleAAC practices (i.e., assessment, implementation, and consultation); determine the communication competence levels achieved by Tele-AAC users; discern stakeholders' perceptions of Tele-AAC services (e.g., acceptability and viability); maximize Tele-AAC's capacity to engage multiple team members in AAC assessment and ongoing service; identify the limitations and barriers of Tele-AAC provision; and develop potential solutions.

\section{RESOLVED:}

That this Resolution of the August 4, 2012, Tele-AAC Working Group, ISAAC Research Symposium, Pittsburgh, PA, USA be disseminated widely via the ISAAC website, relevant professional listservs and websites, and as a Working Group Report in an open source journal on telerehabilitation.

\section{APPROVED:}

August 4, 2012, Tele-AAC Working Group, ISAAC Research Symposium, Pittsburgh, PA, USA.

\section{SIGNATORIES:}

Kate Anderson, B. App. Sc. (Hons), MSPAA, University of Sydney, Australia

Michelle K. Boisvert, PhD. CCC-SLP, University of Massachusetts, Amherst, MA

Janis Doneski-Nicol, MS, CCC-SLP, ATP, Institute for Human Development, Northern Arizona University, Flagstaff, AZ

Michelle L. Gutmann, PhD, CCC-SLP, Department of Hearing and Speech Sciences, Vanderbilt University, Nashville, TN

Nerissa C. Hall, MA.CCC-SLP, University of Massachusetts, Amherst, MA

Cynthia Morelock, MS, CCC-SLP, The Children's Institute of Pittsburgh, Pittsburgh, PA

Richard Steele, PhD, Lingraphica, Princeton, NJ

Ellen R. Cohn, PhD, CCC-SLP, School of Health and Rehabilitation Sciences, University of Pittsburgh, Pittsburgh, PA 


\section{REFERENCES:}

1. Binger, C \& Light, J. (2006). Demographics of preschoolers who require AAC. Language, Speech, \& Hearing Services in Schools, 37, 200-208. Vol.37 200208.

2. Boisvert, M., Lang, R., Andrianopoulos, M., \& Boscardin, M L. (2010). Telepractice in the assessment and treatment of individuals with autism spectrum disorders: A systematic review. Developmental Neurorehabilitation, 13, 423-432.

3. Beukelman, DR, \& Mirenda, P. (2012). Augmentative \& Alternative Communication: Supporting children and adults with complex communication needs. Baltimore: Paul H. Brookes Publishing Company.

4. Goldbart, J., \& Marshall, J. (2004). "Pushes and pulls" on the parents of children who use AAC. Augmentative and Alternative Communication, 20, 194-208.

5. Hirdes, J P., Ellis-Hale, K, \& Pearson Hirdes, B. (1993). Prevalence and policy implications of communication disabilities among adults. Augmentative and Alternative Communication, 9, 273-280.

6. lacono, T. \& Cameron, M. (2009). Australian speechlanguage pathologists' perceptions and experiences of Augmentative and Alternative Communication in early childhood intervention. Augmentative and Alternative Communication, 25, 236-249.

7. Kairy D., Lehoux, P., \& Vincent, C. (2009). A systematic review of clinical outcomes, clinical process, healthcare utilization and costs associated with telerehabilitation. Disability Rehabilitation, 31, 427-447.

8. Marshall, J., \& Goldbart, J. (2008). 'Communication is everything I think.' Parenting a child who needs Augmentative and Alternative Communication (AAC). International Journal of Language and Communication Disorders, 43, 77-98.

9. Mashima, P A., \& Doarn, C R. (2008). Overview of telehealth activities in speech-language pathology. Augmentative and Alternative Communication, 14, 11011117.

10. lacono, T. \& Cameron, M. (2009). Australian speechlanguage pathologists' perceptions and experiences of Augmentative and Alternative Communication in early childhood intervention. Augmentative and Alternative Communication, 25, 236-249.

11. Matas, J A., Mathy-Laikko, P., Beukelman, D R., \& Legresley, K. (1985). Identifying the non-speaking population: A demographic study. Augmentative and Alternative Communication, 1, 17-31.

12. McNaughton, D., Rackensperger, T., Benedek-Wood, E., Krezman, C., Williams, M. \& Light, J. (2008). "A child needs to be given a chance to succeed": Parents of individuals who use AAC describe the benefits and challenges of learning AAC technologies. Augmentative and Alternative Communication, 24, 43-55.

13. World Health Organization \& World Bank. (2011). World report on disability. Available at: http://whqlibdoc.who. int/publications/2011/9789240685215_eng.pdf 